\title{
Commentary: Effects of different lipoprotein apheresis methods on serum protein levels
}

\author{
Ulrich Julius ${ }^{1 *}$
}

'Lipidology and Center for Extracorporeal Treatment, Department of Internal Medicine III, University Hospital Carl Gustav Carus at the Technische Universität Dresden, Germany Fetscherstr. 74, 01307 Dresden (Germany)

\section{Article Info}

\section{Article Notes}

Received: April 08, 2018

Accepted: May 04, 2018

\section{*Correspondence:}

Dr. Ulrich Julius, Lipidology and Center for Extracorporeal Treatment, Department of Internal Medicine III,

University Hospital Carl Gustav Carus at the Technische

Universität Dresden, Germany

Fetscherstr. 74, 01307 Dresden (Germany);

Telephone: +493514582306;

Fax: +493514585306

E-mail: ulrich.julius@uniklinikum-dresden.de

(C) 2018 Julius U. This article is distributed under the terms of the Creative Commons Attribution 4.0 International License.

\section{Keywords}

Lipoprotein apheresis

Total serum protein

Fibrinogen

Albumin

Immunoglobulins

Ferritin

Transferrin
Role of lipoprotein apheresis in high-risk patients with cardiovascular diseases

Lipoprotein apheresis (LA) aims at removing atherogenic lipoproteins from the bloodstream: low-density lipoproteins (LDL), lipoprotein(a) $(\operatorname{Lp}(\mathrm{a}))$. In this way, the development of atherosclerotic plaques can be prevented (e. g. in patients with homozygous or heterozygous familial hypercholesterolemia) or the progression of atherosclerotic lesions can be stopped (within secondary prevention, after a cardiovascular event). In some patients, even a regression of plaques has been seen. As a result of non-progression or regression, no new cardiovascular events (CVE) occur. An effective reduction of CVE has been demonstrated in prospective studies, both in hypercholesterolemic patients and in patients with elevated $\operatorname{Lp}(\mathrm{a})$ levels $\mathrm{s}^{1-3}$. In homozygous familial hypercholesterolemia LA treatment is life-saving ${ }^{4}$.

Before starting the extracorporeal therapy, all other therapeutic approaches have to be applied (optimal diet; statins, ezetimibe, bile acid sequestrants, Proprotein convertase subtilisin/kexin type 9 (PCSK9) inhibitors when tolerated). Other atherogenic risk factors - a positive family history for early CVE in first-degree relatives, hypertension, diabetes mellitus, obesity, renal insufficiency, smoking, low physical activity - contribute to the vascular risk.

In the 1960ies, a total plasma exchange was used to treat patients with homozygous familial hypercholesterolemia ${ }^{5}$. Later, more specific LA methods were developed ${ }^{6}$ which avoid the major problem of total plasma exchange: all proteins are removed and replaced by either albumin or plasma from other people. Allergic reactions have been observed.

\section{Different lipoprotein apheresis methods}

LA methods are based on the following principles to remove atherogenic lipoproteins: ${ }^{7}$

- Precipitation: an excess of heparin in an acidic milieu (HELP)

- Adsorption:

- Antibodies against apolipoprotein B (TheraSorb ${ }^{\mathrm{TM}}$ LDL) or $\operatorname{Lp}(\mathrm{a})$ (Lp(a) Lipopak(R) adsorption)

- Negatively charged surface:

- Polyacrylate-coated polyacrylamide beads (DALI) 
- Dextrane sulfate (Liposorber D and LA-15)

- Filtration: The first filter separates plasma, the second filter retains big molecules (Lipidfiltration and MONET)

For details of the methods (devices, blood flow, treated volume, anticoagulation, adverse effects) see the literature ${ }^{7}$ ${ }^{8}$. In general, LA therapy is rather expensive and laborious.

Some LA methods need a plasma separation as a first step, others work with whole blood.

\section{Pleiotropic effects of lipoprotein apheresis}

In addition to the effects on lipoproteins, all LA methods also exert other effects: ${ }^{7,9}$

1. Decrease in fibrinogen and other coagulatory and fibrinolytic markers

2. Decrease in C-reactive protein and other inflammatory markers

\section{Decrease in oxidized LDL particles}

4. Reduction in the expression of the proatherosclerotic oxLDL receptor LOX-1 and adhesion molecule VCAM1 and increase in the expression of vasoprotective and nitric oxide generating endothelial nitric oxide synthase in human endothelial cells in response to serum of hypercholesterolemic patients.

5. Reduction in the activity of oxidized phospholipids and lipoprotein-associated phospholipase A2, which are bound to $\operatorname{Lp}(\mathrm{a})$

6. Effects on the positively charged proinflammatory apolipoprotein E4

7. Effects on shear stress-dependent platelet adhesion

8. Effects on fatty acid-binding protein 4

9. Decrease in serum PCSK9 levels
10. Improvement of coronary blood flow

11. Improvement of retinal blood flow

\section{Summary of results shown in our paper ${ }^{10}$}

This study included 75 patients (46 males, 29 females; mean age 62.6 years (range 29 - 81 years); the majority of whom had been treated with LA for several years. We used 6 different LA methods (see Figure 1; marked with green flags). These methods differ with respect to underlying removal technique for lipoproteins and with respect to treated volume (plasma, whole-blood). Before and after one LA session additional blood was drawn in order to check protein concentrations. Usual lab methods to measure protein concentrations have been used. Because all LA methods need a saline infusion in order to return the extracorporeal plasma / blood to the patient, a hemodilution takes place. That is why all protein concentrations measured after LA sessions have been corrected for parallel changes in the hematocrit.

Table 1 and Table 2 summarize the acute reduction rates of different proteins observed when using different LA methods.

\section{Mechanisms underlying the removal of additional proteins}

It was found that HELP and the filtration methods affect protein concentrations significantly more than the wholeblood LA methods.

The following mechanisms may explain the removal of additional proteins (besides lipoproteins):

Other proteins are also precipitated (HELP), cannot pass the second filter (Lipidfiltration and MONET), are adsorbed to the negatively charged surface (DALI and Liposorber D), are washed out of the columns with saline into the eluate when switching from one column to the other one (TheraSorb ${ }^{\mathrm{TM}} \mathrm{LDL}$ )

\begin{tabular}{|c|c|c|c|c|c|c|c|c|c|}
\hline LA method & Fibrinogen & $\begin{array}{c}\text { Total } \\
\text { protein }\end{array}$ & Albumin & $\begin{array}{c}\text { Alpha 1 } \\
\text { globulin }\end{array}$ & $\begin{array}{c}\text { Alpha 2 } \\
\text { globulin }\end{array}$ & $\begin{array}{c}\text { Beta } \\
\text { globulin }\end{array}$ & $\begin{array}{c}\text { Gamma } \\
\text { globulin }\end{array}$ & Ferritin & Transferrin \\
\hline HELP & -57 & -13 & -11 & -8 & -13 & -27 & -9 & -10 & -10 \\
\hline TherLDL & -18 & -11 & -8 & -9 & -18 & -19 & -15 & -10 & -9 \\
\hline DALI & -21 & -9 & -6 & -8 & -6 & -24 & -14 & -7 & -6 \\
\hline LF & -47 & -14 & -10 & -11 & -22 & -27 & -19 & -24 & -10 \\
\hline LipoD & -20 & -8 & -5 & -3 & -7 & -27 & -9 & -5 & -6 \\
\hline MONET & -50 & -14 & -10 & -6 & -26 & -28 & -22 & -34 & -10 \\
\hline
\end{tabular}

Abbreviations: HELP, heparin-induced extracorporeal LDL precipitation; TherLDL, TheraSorb ${ }^{T M}$ LDL; LF, lipidfiltration; DALI, direct adsorption of lipoproteins; LipoD, Liposorber D; MONET, membrane filtration optimized novel extracorporeal treatment

The highest reductions were seen for fibrinogen (with HELP and filtration methods), for beta globulins (with all methods), and for ferritin (with filtration methods).

Table 1: Acute effects of different LA methods on protein concentrations (mean reductions in \%; the post-LA concentrations have been corrected for changes of the hematocrit) 


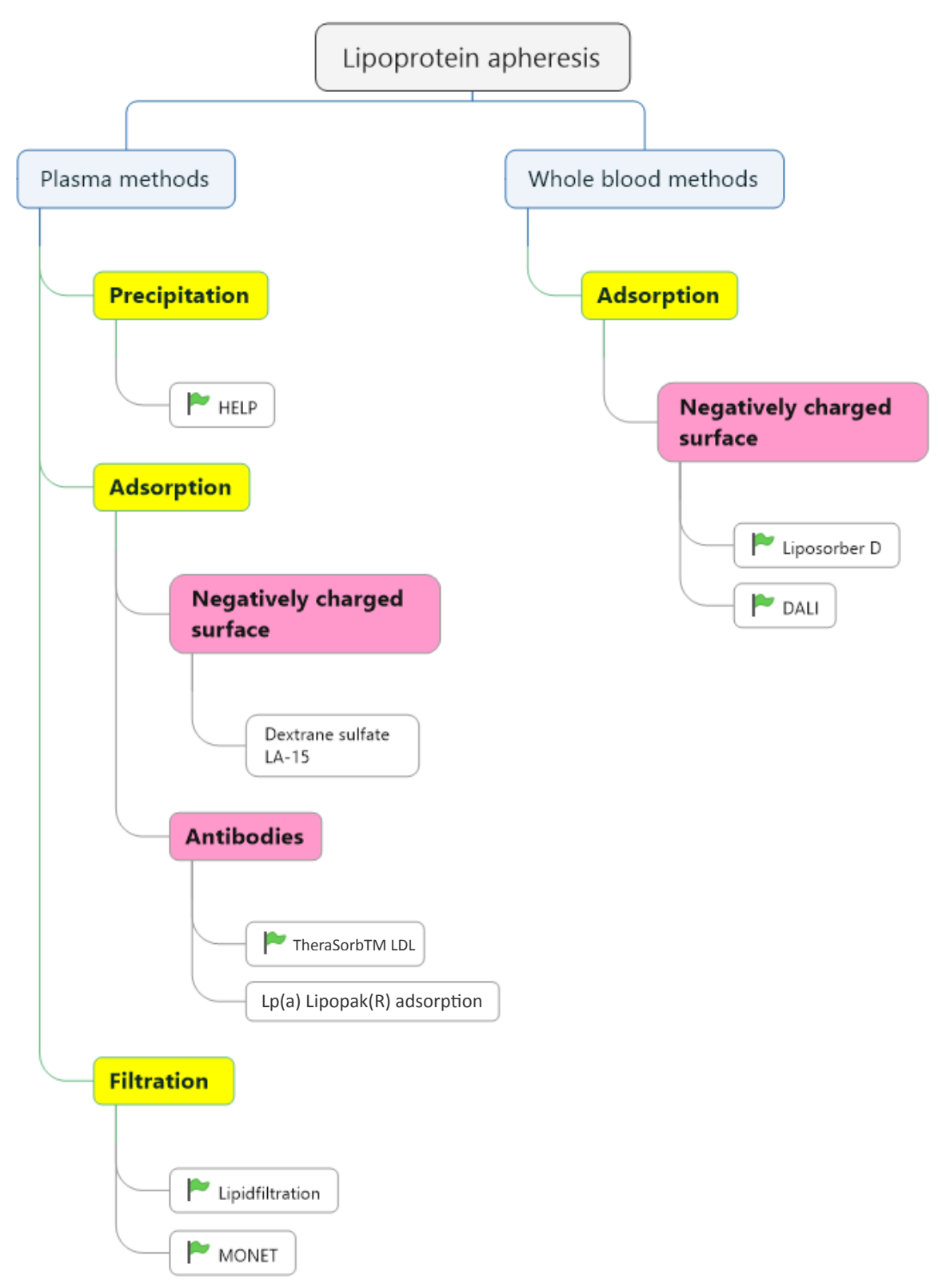

Abbreviations: HELP, heparin-induced extracorporeal LDL precipitation; DALI, direct adsorption of lipoproteins; MONET, membrane filtration optimized novel extracorporeal treatment

The Lp(a) Lipopak $\left(\left(^{R}\right)\right)$ columns reduce only Lp(a) particles, whereas all the other LA methods acutely decrease LDL-cholesterol and Lp(a) levels.

Figure 1: LA methods (those which are used at our center are marked with a green flag)

With respect to removing apolipoprotein B-containing lipoproteins, the TheraSorb ${ }^{\mathrm{TM}} \mathrm{LDL}$ system is the most specific one, additional proteins get lost to a much lower degree, similar to the whole-blood LA methods.

Consequences of effects of LA on serum protein levels

\section{Rheological properties}

The decrease of fibrinogen and of circulating lipoproteins improves the rheological properties of the blood. An increased perfusion has been measured in the heart following an LA session ${ }^{11}$. We had successfully treated patients with a diabetic foot syndrome who exhibited very high fibrinogen concentrations with the HELP system ${ }^{12}$.

\section{Anticoagulation}

The effect of LA methods on fibrinogen (especially with HELP and filtration methods) involves a certain danger of bleeding. HELP also has a definite impact on factors belonging to the prothrombin complex (II, VII, X) ${ }^{13}$. In patients taking an oral anticoagulant the HELP treatment 


\begin{tabular}{|l|c|c|c|}
\hline LA method & IgA & IgM & IgG \\
\hline HELP & -11 & -12 & -16 \\
\hline TherLDL & -13 & -16 & -19 \\
\hline DALI & -8 & -16 & -20 \\
\hline LF & -24 & -45 & -26 \\
\hline LipoD & -8 & -12 & -17 \\
\hline MONET & -23 & -41 & -19 \\
\hline
\end{tabular}

Abbreviations: HELP, heparin-induced extracorporeal LDL precipitation; TherLDL, TheraSorb ${ }^{\mathrm{TM}} \mathrm{LDL}$; $\mathrm{LF}$, lipidfiltration; DALI, direct adsorption of lipoproteins; LipoD, Liposorber D; MONET, membrane filtration optimized novel extracorporeal treatment; IgA, immunoglobulin A; IgM, immunoglobulin $\mathrm{M}$; IgG, immunoglobulin $\mathrm{G}$

Table 2: Acute effects of different LA methods on immunoglobulin concentrations (mean reductions in \%; the post-LA concentrations have been corrected for changes of the hematocrit)

sometimes may induce high INR values that is why we switched these patients to another LA system.

\section{Edema}

The decrease of albumin may contribute to the development of edema which is observed in some patients at the end of an LA session.

\section{Iron deficiency}

The reduction of ferritin and of transferrin may aggravate an iron deficit which is often seen in LA patients ${ }^{14}$.

\section{Removal of pathogenic immunoglobulins}

In particular, the filtration methods have been used to eliminate pathogenic antibodies ${ }^{15}$. Recently we treated a woman who suffered from a severe coronary heart disease, associated with rather high LDL-C levels and statin intolerance, and a concomitant myasthenia gravis. Sessions with MONET led to a relevant improvement of the clinical picture of the immunological disease and a significant reduction of the antibodies. Intravenous infusions of immunoglobulins could almost be stopped in this patient.

\section{Infections because of low concentrations of immunoglobulins}

We did not observe an increased frequency of infectious diseases among our LA patients. Though it makes sense to measure immunoglobulin concentrations in patients who are treated with filtration methods. In patients on MONET therapy, the pre-LA immunoglobulin M levels were below the normal range. At our center, we also perform immunoadsorption with columns with antibodies against immunoglobulins ${ }^{16}$. In these patients, we did not see infections.

\section{Conclusions}

The so-called "specific" LA methods also reduce other proteins besides lipoproteins. The amount of serum protein removal differs between LA methods used. HELP, using a precipitation, and the filtration methods (Lipidfiltration, MONET) exert more marked effects than the other LA methods. Rheological properties improve immediately after LA sessions. The removal of immunoglobulins may have beneficial consequences (with respect to eliminating pathogenic antibodies) but the immunoglobulin concentrations should be carefully monitored. Of course, when comparing with total plasma exchange, the main advantage of all LA methods is the fact that no proteins from somebody else have to be given. A total plasma exchange can be performed in patients with a chylomicronemia syndrome who suffer from an acute pancreatitis (one or two sessions needed). But this therapeutic approach should be avoided when treating high-risk patients over the years. An LA center should work with several LA methods - thus offering the opportunity to switch to another method in patients who show an insufficient lipid-lowering efficiency or who suffer from adverse effects 9 .

\section{Conflicts of Interest}

Honoraria from Aegerion, Amgen, Chiesi, Sanofi, Kaneka, Diamed, Fresenius Medical Care

\section{References}

1. Mabuchi H, Koizumi J, Shimizu M, et al. Long-term efficacy of lowdensity lipoprotein apheresis on coronary heart disease in familial hypercholesterolemia. Hokuriku-FH-LDL-Apheresis Study Group. Am J Cardiol. 1998; 82(12): 1489-95.

2. Leebmann J, Roeseler E, Julius $U$, et al. Lipoprotein apheresis in patients with maximally tolerated lipid-lowering therapy, lipoprotein(a)-hyperlipoproteinemia, and progressive cardiovascular disease: prospective observational multicenter study. Circulation. 2013; 128(24): 2567-76.

3. Roeseler E, Julius U, Heigl F, et al. Lipoprotein Apheresis for Lipoprotein(a)-Associated Cardiovascular Disease: Prospective 5 Years of Follow-Up and Apo(a) Characterization. Arterioscler Thromb Vasc Biol. 2016; 36(9): 2019-27.

4. Thompson GR, Seed M, Naoumova RP, et al. Improved cardiovascular outcomes following temporal advances in lipid-lowering therapy in a genetically-characterised cohort of familial hypercholesterolaemia homozygotes. Atherosclerosis. 2015; 243(1): 328-33.

5. de Gennes JL, Touraine R, Maunand B, et al. [Homozygous cutaneotendinous forms of hypercholesteremic xanthomatosis in an exemplary familial case. Trial of plasmapheresis as heroic treatment]. Bull Mem Soc Med Hop Paris. 1967; 118(15): 1377-402.

6. Julius U. History of lipidology and lipoprotein apheresis. Atheroscler Suppl. 2017; 30: 1-8.

7. Julius U. Lipoprotein apheresis in the management of severe hypercholesterolemia and of elevation of lipoprotein(a): current perspectives and patient selection. Med Devices (Auckl). 2016; 9: 349-60.

8. Dittrich-Riediger J, Schatz U, Hohenstein B, et al. Adverse events of lipoprotein apheresis and immunoadsorption at the Apheresis Center at the University Hospital Dresden. Atheroscler Suppl. 2015; 18: 4552. doi: 10.1016/j.atherosclerosissup.2015.02.007.:45-52.

9. Julius U, Fischer S, Schatz U, et al. Why an apheresis center should offer more than one lipoprotein apheresis method. Ther Apher Dial. 2013; $17(2): 179-84$. 
10. Julius U, Siegert G, Kostka H, et al. Effects of different lipoprotein apheresis methods on serum protein levels. Atheroscler Suppl. 2015; 18: 95-102. doi: 10.1016/j.atherosclerosissup.2015.02.018.:95-102.

11. Khan TZ, Hsu LY, Arai AE, et al. Apheresis as novel treatment for refractory angina with raised lipoprotein(a): a randomized controlled cross-over trial. Eur Heart J. 2017; 38(20): 1561-9.

12. Rietzsch H, Panzner I, Selisko T, et al. Heparin-induced Extracorporal LDL precipitation (H.E.L.P) in diabetic foot syndrome - preventive and regenerative potential. Horm Metab Res. 2008; 40(7): 487-90.

13. Julius U, Siegert G, Gromeier S. Intraindividual comparison of the impact of two selective apheresis methods (DALI and HELP) on the coagulation system. Int J Artif Organs. 2000; 23(3): 199-206.

14. Schatz U, Illigens BM, Siepmann T, et al. TIDILAP: Treatment of iron deficiency in lipoprotein apheresis patients - A prospective observational multi-center cohort study comparing efficacy, safety and tolerability of ferric gluconate with ferric carboxymaltose. Atheroscler Suppl. 2015; 18: 199-208. doi: 10.1016/j. atherosclerosissup.2015.02.030.:199-208.

15. Otsubo S, Tanabe K, Shinmura H, et al. Effect of post-transplant double filtration plasmapheresis on recurrent focal and segmental glomerulosclerosis in renal transplant recipients. Ther Apher Dial. 2004; 8(4): 299-304.

16. Hohenstein B, Passauer J, Ziemssen T, et al. Immunoadsorption with regenerating systems in neurological disorders - A single center experience. Atheroscler Suppl. 2015; 18: 119-23. doi: 10.1016/j. atherosclerosissup.2015.02.022.:119-23. 